
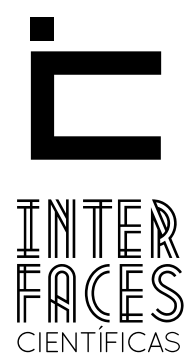

DIREITO

\title{
CONTRIBUIÇÕES PARA A INCORPORAÇÃO DA PERSPECTIVA DE GÊNERO NO PARLAMENTO
}

\author{
Salete Maria da Silva ${ }^{1}$
}

\section{RESUMO}

A igualdade de gênero, prevista na legislação brasileira desde o advento da Constituição Federal de 1988 , exige que mudanças estruturais e culturais sejam permanentemente estimuladas e desenvolvidas no seio da sociedade, no âmbito do Estado e de suas instituições, a fim de que este princípio jurídico, de natureza constitucional, seja plenamente observado e vivenciado por mulheres e homens em suas relações sociais. Neste sentido, dentre os tantos desafios que esta igualdade impõe, exsurge a imperiosa necessidade dos próprios Parlamentos - isto é, as Casas Legislativas onde as leis são elaboradas e onde os direitos são, portanto, proclamados e reconhecidos se transformarem em espaços sensíveis às questões de gênero, ou seja, onde a perspectiva de gênero seja incorporada como condição indispensável à existência, à composição e ao próprio funcionamento destas instâncias discursivas, deliberativas e constitutivas da vontade política que caracteriza a democracia pluralista dos dias atuais. Visando contribuir com este debate, o presente texto, que se apoia nas reflexões produzidas pelo feminismo jurídico, não somente chama a atenção para a atualidade e importância da incorporação da visão de gênero no Parlamento, como também apresenta, em linhas gerais, algumas sugestões sobre como fazê-lo.

\section{PALAVRAS-CHAVE}

Gênero. Parlamento. Feminismo. Perspectivismo. Legislação. 


\section{ABSTRACT}

Gender equality, under Brazilian law since the advent of the 1988 Federal Constitution, which requires structural and cultural changes are continuously stimulated and developed within society, within the State and its institutions, so that this legal principle, of a constitutional nature, is fully observed and experienced by women and men in their social relations. In this sense, among the many challenges it imposes equality, stands the urgent need of their own parliaments - that is, the Legislative Houses where laws are made and where the rights are thus proclaimed and recognized - to change into sensitive areas to gender issues, that is where the gender perspective is incorporated as a prerequisite to the existence, composi- tion and proper functioning of these discursive, deliberative and constitutive instances of political will which characterizes the pluralist democracy of today. To contribute to this debate, this text, which is based on the reflections produced by the legal feminism, not only draws attention to the relevance and importance of gender view of incorporation in Parliament, but also shows, in general terms, some suggestions on how to do it.

\section{KEYWORDS}

Genre. Parliament. Feminism. Perspectivism. Legislation.

\section{RESUMEN}

La igualdad de género, presente en la Constitución Federal de 1988, requiere permanentes cambios de naturaleza estructural y cultural en el marco de la sociedad, del Estado y de sus instituciones para que se cumpla por completo el principio constitucional referido y para que las mujeres y los hombres pueden vivir en igualdad en sus relaciones sociales. En este sentido, entre los muchos desafíos que impone la igualdad, y surge el imperativo de cambios en los propios parlamentos - es decir, las Cámaras Legislativas, donde se hacen las leyes y, por tanto, donde se proclaman y se reconocen los derechos - deben convertirse en áreas sensibles a las cuestiones de género, es decir, donde la perspectiva de género se incorpore como requisito previo para la existencia, composición y funcionamiento adecuado de estas instancias discursivas, deliberativas y constitutivas de la voluntad política que caracteriza a la democracia pluralista del día actual. Para contribuir a este debate, este texto, que se basa en el pensamiento jurídico feminista, no sólo llama la atención sobre la relevancia e importancia de la incorporación de la visión de género en el Parlamento, al igual que, en general, hace algunas sugerencias sobre cómo hacerlo.

\section{PALABRAS CLAVE}

Género. Parlamento. Feminismo. Perspectivismo. Legislación. 


\section{INTRODUCÇÃO}

0 pensamento feminista ${ }^{2}$, enquanto teoria compreensiva e, sobretudo, transformadora das relações de gênero desiguais, é constituído por uma gama de reflexões e posições teóricas que nos auxiliam no entendimento e na subversão da realidade social. (BIRGIN, 2000; HARDING, 2004; SARDENBERG \& COSTA, 2002). No bojo deste pensamento, emerge uma corrente denominada pensamento jurídico feminista ${ }^{3}$ (ou feminismo jurídico, como é mais conhecida) que, dentre outras ações, problematiza as teorias jurídicas e políticas tradicionais e hegemônicas, acusando-as de refletirem não apenas a sua origem antidemocrática, mas o seu viés androcêntrico e, por isso mesmo, sexista (FACIO \& FRIES, 1999; SMART, 2000; MENACHE, 2005).

O feminismo jurídico, assim como sua base teórico-filosófica, propõe outra forma de se ver e de se viver no mundo, aportando novas contribuições para a organização e o desenvolvimento da vida em sociedade. Dentre estas contribuições, emerge o conceito de perspectiva de gênero que, segundo Menache (2005) é, ao mesmo tempo, um enfoque e uma ferramenta de análise adotada internacionalmente com vistas a garantir a igualdade de gênero e contribuir para um maior e melhor desenvolvimento social. Para Piovesan (2009), o enfoque de gênero constitui, ainda, um dos atuais esforços políticos da Organização das Nações Unidas, que busca integrar as demandas e as experiências tanto das mulheres como de homens no desenho, na implementação e na avalia-

2. O pensamento feminista é bastante amplo, diverso, complexo e plural. Tem se desenvolvido graças aos esforços de militantes, ativistas, pensadoras, pesquisadoras e professoras universitárias assumidamente feministas. É percebido como teoria, filosofia e compreensão da história e das realidades sociais. Apresenta-se também como uma proposta política de transformação das relações de gênero.

3. Dentre as representantes do pensamento jurídico feminista, merece destaque a jurista costarricense Alda Facio (1999), por ser uma de suas maiores entusiastas e por sua profícua produção na área. No entanto, também merece registro o contributo de outras autoras, espalhadas por diversos países e continentes, que também tem se dedicado ao desenvolvimento e à difusão deste pensamento, tais como Tove Stang Dahl, na Noruega (1993), Robin West, nos Estados Unidos (2000), Maria Luisa Balaguer (2005), na Espanha, Carol Smart (2000), no Reino Unido, Beatriz Koheh (2000), na Itália, Lilia Ullloa, Claudia Dominguez e Lourdes Henriquez (2007), no México, Lorena Fries (1999), no Chile, Haydée Birgin (2000), na Argentina, além de Valéria Pandjiariian (2008) e Flávia Piovesan (2002), dentre outras, no Brasil. ção de leis, programas e políticas públicas de uma forma geral ${ }^{4}$.

Vale destacar que o pensamento jurídico feminista, por meio do seu esforço em prol da incorporação do enfoque de gênero no âmbito estatal, tem sido adotado não somente para pensar o Direito, enquanto conjunto de normas positivadas, mas enquanto discurso e práxis jurídica profundamente marcados pela estratificação genérica. Ademais, o feminismo jurídico tem contribuído para os debates relacionados ao processo de elaboração das leis, razão porque, neste artigo, o invocamos para embasar o argumento da necessidade de incorporação da perspectiva de gênero no Parlamento.

De acordo com a perspectiva de gênero, a situação das mulheres, ou seja, suas necessidades e experiências específicas, devem ser tomadas em conta durante a feitura e, sobretudo, na aplicação das normas jurídicas, para o quê, segundo Ulloa (2007), faz-se necessário reconhecer que as relações entre homens e mulheres não são relações de igualdade, mas, ao contrário, são relações caracterizadas pela desigualdade, discriminação, opressão, exploração e, principalmente violência.

Em face do exposto, o pensamento feminista de um modo geral, e o pensamento jurídico feminista em particular, propugna pela distribuição igualitária de bens, serviços, oportunidades e direitos, o que somente será possível, levando em consideração o status quo social e construindo mecanismos para a transformação do mesmo, no que a legislação pode e deve cumprir um papel fundamental (MENACHE, 2005).

4.Enquanto orientação para todas as Nações, a perspectiva de gênero está contida nas conclusões da reunião do Conselho Econômico, e Social da ONU ocorrida em 1997. Este enfoque visa englobar todas as atividades relacionadas com a paz, com o desenvolvimento e com os direitos humanos, assegurando que mulheres e homens possam influir, participar e se beneficiar dos mesmos de maneira igual, sem desequilíbrios. Nos marcos da IV Conferência Mundial sobre a Mulher, ocorrida em 1995, foi aprovada a incorporação da perspectiva de gênero como um elemento fundamental para o êxito dos compromissos sobre igualdade de gênero, incluídos aqueles da Declaração e da Plataforma de Beijin. Vale destacar que dentre estes compromissos, se encontram os da Declaração do Milênio e diversas outras resoluções e decisões da Assembleia Geral das Nações Unidas (PIOVESAN, 2009). 
Sendo assim, considerar a experiência feminina, reconhecendo, sobretudo, suas necessidades e especificidades, conferindo vez e voz às mulheres no âmbito legislativo, quer como parlamentares, que como destinatárias/beneficiárias das leis e atos normativos, significa incorporar a perspectiva de gênero no âmbito do Parlamento ou, mais do que isto, significa construir formas de se debelar a opressão e a dominação patriarcal presente em todas as esferas de poder, inclusive nas Casas Legislativas (SILVA, 2012).

Além do exposto, o desenvolvimento de teorias e métodos radicalmente diferenciados dos tradicionais, que em sua maioria correspondem à visão positivista e androcêntrica de mundo, contribui para o aprimoramento das relações humanas e para o desenvolvimento das instituições políticas, a quem compete salvaguardar os mais elementares princípios democráticos de inclusão e participação social. É, portanto, inspirada nesta compreensão que este texto apresenta e discute, teórica e metodologicamente, a perspectiva de gênero - fruto do pensamento feminista - e alguns exemplos de metodologias de incorporação desta visão no âmbito do Parlamento.

\section{RELEVÂNCIA DA PERSPECTIIVA DE GÊNERO NO PARLAMENTO}

De uma maneira geral, a reflexão sobre gênero se faz relevante nas atividades legislativas porque não somente favorece a aquisição de uma consciência de gênero ${ }^{5}$ entre os(as) parlamentares, funcionários(as) e assessores(as), como possibilita a ampliação do alcance das leis ou atos normativos por estes(as) elaborados, contribuindo, assim, para o aprimoramento da democracia e para o

5. A consciência de gênero (GAMBA, 2007; COSTA, 1998) decorre da percepção que cada indivíduo tem acerca de sua condição e posição social, enquanto mulher ou homem. Tal consciência implica o reconhecimento das desigualdades presentes no âmbito das sociedades patriarcais, como é o caso do Brasil, onde as realidades vividas pelos sujeitos do sexo feminino resultam de relações de gênero hierárquicas, antidemocráticas e, portanto, iníquas. cumprimento do papel do Estado ${ }^{6}$ nas sociedades contemporâneas (SILVA, 2012).

Outra razão que justifica a incorporação de uma visão de gênero no Parlamento (seja no âmbito municipal, estadual ou federal) é o fato de que em nosso país, a exemplo de outros países do Ocidente, a $\operatorname{Lei}^{7}$ é a principal fonte do Direito, sendo, por excelência, o instrumento por meio do qual são formalizadas as conquistas jurídicas que obrigam tanto o Estado como a sociedade a respeitar e fazer cumprir os direitos e obrigações inscritos ou positivados no pacto social constitucionalmente firmado.

Além disto, por se tratar de uma temática que transversaliza todas as áreas e setores da produção legislativa, as questões de gênero não devem ser vistas como assunto exclusivo da bancada feminina ${ }^{8}$ afinal, as demandas das mulheres dizem respeito a toda a sociedade, vez que aquelas constituem mais da metade da composição desta e, conforme atestam diversos indicadores, se encontram em situação de desvantagem nos diversos setores da vida social, inclusive na composição do próprio Parlamento (SILVA, 2012).

É, portanto, muito importante incorporar a perspectiva de gênero na atividade parlamentar/legislativa, pois somente assim será possível construir leis que possibilitem e/ou garantam não somente a igual-

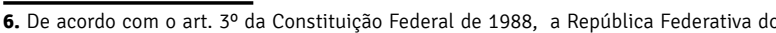
Brasil assumiu , dentre outros objetivos fundamentais, a tarefa de "construir uma sociedade livre, justa e solidária" bem como de "promover o bem de todos, sem preconceitos de origem, raça, sexo, cor, idade e quaisquer outras formas de discriminação". Sendo assim, passa a ser responsabilidade do Estado brasileiro o desenvolvimento de políticas de caráter universal assim como de medidas afirmativas tendentes a assegurar o bem-estar social e a igualdade de direito e oportunidades para mulheres e homens em todos os âmbitos de suas vidas.

7. A legislação tem um papel importante na sociedade porque, a um só tempo, resguarda os direitos (das pessoas e dos grupos frente ao Estado e aos demais indivíduos e instituições) e compromete e obriga o próprio Estado a garantir tais conquistas por meio de suas políticas, ações e responsabilidades.

8. A bancada feminina é constituída pelo conjunto de mulheres parlamentares em cumprimento de mandato em determinada Casa Legislativa. $\mathrm{Na}$ atual legislatura, a bancada feminina da Câmara dos Deputados está composta por 45 parlamentares. Os nomes das parlamentares, a unidade da federação que representam e o seu partido político podem ser verificados no portal da Câmara dos Deputados. Disponível em: http://www2.camara.leg.br/a-camara/conheca/camara-destaca/mulheresno-parlamento/bancada-feminina. 
dade, mas a equidade de gênero, ${ }^{9}$ já que as normas jurídicas, de um modo geral, ao longo da história, se prestaram mais a excluir do que a incluir os grupos socialmente vulneráveis ou subjugados, tais como mulheres, negros, indígenas, crianças, deficientes, dentre outros. ${ }^{10}$

\section{PARLAMENTOS E LEGISLAÇÕES IINJSENSÍVEIS AO GÊNERO}

Conforme foi destacado, as atividades legislativas e parlamentares poderão ser mais eficientes no cumprimento de seus objetivos se adotarem e operarem com uma visão de gênero ao longo do seu percurso; afinal, segundo as diversas análises feministas sobre o Parlamento nacional e as leis vigentes e/ou revogadas no Brasil, a perspectiva androcêntrica ${ }^{11}$ levou à produção de muitas normas insensíveis ou cegas ao gênero ${ }^{12}$, sendo ainda recente e diminuta a quantidade de leis que contemplam as especificidades e necessidades femininas (TELES, 1999).

Vale lembrar, no entanto, que as leis que contemplam as demandas femininas no Brasil são resultantes da incidência política dos movimentos feministas e de mulheres no âmbito e no entorno do Parlamen-

9. Apesar de haver muita confusão quanto a utilização destes conceitos, o pensamento feminista vem consensuando que a igualdade de gênero seria o usufruto, em iguais condições, de direitos e oportunidades por homens e mulheres; sendo que a equidade de gênero corresponderia à justiça social no tratamento das mulheres e homens, especialmente no que diz respeito ao acesso e controle de direitos, obrigações, benefícios e oportunidades (GAMBA, 2007, p. 28).

10. Durantes séculos, por força do sistema patriarcal que se estribava, dentre outros mecanismos, na produção e no discurso jurídico, as leis contribuíram para a manutenção do status quo social, vindo paulatinamente (e por conta das lutas dos diversos movimentos sociais, dentre eles o feminismo), a se transformar em instrumentos de emancipação e transformação da realidade. No que se refere à questão feminina, desde a Revolução Francesa, as mulheres reivindicam o reconhecimento de direitos, denunciando o caráter iníquo das leis e das Constituições estatais (COSTA, 2005). 11. Esta palavra vem do termo androcentrismo que, conforme a teoria feminista, se refere a crenças e tradições culturais centradas na figura do homem, fazendo deste o paradigma do humano. Sob o androcentrismo os interesses e as experiências dos homens são o centro do universo, fazendo com que o conhecimento, as organizações sociais, a análise e investigação dos fatos, as narrativas históricas, as instituições e propostas políticas e tudo o mais que interesse à sociedade seja enfocado unicamente desde a perspectiva masculina, a qual não se assume como parcial, mas como objetiva, imparcial e universal.

12. Diz-se que uma lei é cega ao gênero quando esta não percebe ou desconsidera a existência de diferenças, cultural e socialmente construídas, entre homens e mulheres, as quais são geradoras de desigualdades e injustiças no que se refere ao acesso, participação e controle dos recursos, bens e serviços produzidos socialmente e garantidos juridicamente. to brasileiro. Afinal, nosso país, ao longo de mais de três séculos, viveu sob o domínio da Coroa portuguesa, tendo obtido sua independência política somente em 1822 e sua emancipação jurídica em 1824, com a elaboração da primeira Constituição do país. Nesta primeira Constituição nenhum direito foi conferido às mulheres, sendo correto afirmar que, desde sua origem, o Brasil se estabeleceu como um Estado tremendamente injusto em termos de relações de gênero. Tal realidade, no entanto, não era exclusiva de nossa pátria, pois refletia as condições sociais, políticas e jurídicas da época na Europa e no resto do mundo. Neste período, vigoravam no Brasil as Ordenações do Reino13 que, dentre outras questões, privilegiavam a figura do pater família14 nas leis, nos contratos e nos acordos celebrados exclusivamente entre cavalheiros (SILVA, 2012; COSTA, 2005).

Mesmo com a proclamação da República, e apesar das diversas lutas desenvolvidas por homens e mulheres pertencentes a grupos sociais oprimidos e explorados ao longo da história, as leis constitucionais e/ ou de caráter ordinário seguiram sem reconhecer a cidadania feminina, embora se apresentassem como gerais, universais e imparciais.

Assim, até 1934, quando foi constitucionalizado o voto feminino no Brasil, nenhuma norma reconhecia direitos de cidadania para as mulheres, mas, ao contrário, todas serviam como instrumentos de dominação masculina, uma vez que (justificando as desigualdades de gênero, social e culturalmente construídas), negavam a elas o exercício de prerrogativas explicitamente garantidas aos varões, tais como: direito à participação política, à propriedade privada, ao trabalho,

13. Como se sabe, Ordenações do Reino é o nome que se dá ao conjunto de Leis emanadas do Reino de Portugal, denominadas, cronológica e respectivamente, de: Ordenações Afonsinas (1446-1521); Ordenações Manoelinas (1521-1603) e Ordenações Filipinas (1603-1830).

14. No Direito romano o pai (patriarca) exercia o pater familias, isto é, o direito soberano sobre os demais membros do grupo familiar. Este direito/poder conferia ao homem um status familiar por meio do qual este poderia, soberanamente, dispor até mesmo da vida daqueles que estivessem sob sua tutela ou autoridade. Como herdeiros do dirieto romano, os países de lingua latina elaboraram seus códigos civis baseados nesta perspectiva. Obviamente que nos dias atuais o Código Civil já não adota mais o termo pátrio poder, porém a perspectiva que o originou segue vigente entre nós, como uma espécie de mandato oculto. 
à plena educação, dentre outros. Por tudo isto, graças às lentas, sucessivas e insistentes batalhas organizadas pelos movimentos feministas e de mulheres no Brasil, em 1988, no âmbito da Constituição Cidadã, finalmente foi declarado, textualmente, que homens e mulheres são iguais em direitos e obrigações (SILVA, 2012; COSTA, 2005).

Pelo exposto, é possível perceber que as leis elaboradas pelo parlamento brasileiro, durante centenas de anos, sempre foram insensíveis ou cegas ao gênero, afinal, quando seus conteúdos deixaram de proclamar a suposta neutralidade jurídica, passaram a sustentar a dita igualdade formal, ignorando o tremendo fosso social, político e econômico que gerava (e ainda gera) disparidades entre as condições de vida de mulheres e homens, ou seja, as chamadas brechas de gênero15 que impedem o pleno desenvolvimento pessoal e social de mais da metade da população do país e dificultam a concretização dos objetivos inscritos em sua Lei Maior.

Conforme ficou demonstrado, não é possível haver justiça social sem a elaboração de leis sensíveis ao gênero, isto é, sem normas jurídicas que levem em consideração a situação de mulheres e homens, bem como as relações sociais estabelecidas entre estes, caracterizadas, fundamentalmente, pela discriminação, desigualdade e exclusão, reproduzidas social, institucional e subjetivamente, impedindo o pleno desenvolvimento da democracia e da sociedade como um todo.

Porém, para produzir normas legais sensíveis ao gênero, faz-se primeiramente necessário desenvolver uma clara percepção das desigualdades, discriminações e hierarquias de gênero existentes dentro do próprio Parlamento, todas decorrentes das mentali-

15. A expressão brechas de gênero indica a distância que separa mulheres e homens em termos de oportunidades de acesso e controle de recursos econômicos, sociais e políticos. Sua importância reside na possibilidade de se comparar, quantitativa e qualitativamente, a situação de ambos os sexos diante de variáveis ou características comuns, tais como idade, ocupação, grau de escolaridade, participação política, trabalho, remuneração etc. (GAMBA, 2005). dades, das representações, das relações, das posições e dos papéis que cada mulher e cada homem produz e reproduz nos diversos momentos da vida e no seu cotidiano pessoal e profissional.

Neste sentido, antes de identificar e/ou produzir alguma norma jurídica sensível ao gênero ou garantidora dos direitos das mulheres, convém que os e as parlamentares, assim como os demais servidores das Casas Legislativas, desenvolvam uma reflexão, com enfoque ou lentes de gênero, voltada sobre si mesmos(as), isto é, destinada a identificar o lugar social que cada pessoa ocupa neste espaço deliberativo, e como vem desempenhando suas funções laborais e políticas no âmbito Parlamentar, valendo como estímulo as seguintes indagações: Até que ponto minha visão de mundo influencia o modo como realizo minhas funções parlamentares/legislativas? De que forma minha identidade de gênero e/ou minha posição social nas relações de gênero estabelecidas no âmbito profissional influenciam minhas interpretações e/ou posições diante das propostas de leis nas quais atuo? De que maneira a perspectiva de gênero pode contribuir para o desempenho de minha atividade profissional? Que disparidades ou assimetrias de gênero sou capaz de identificar no meu campo profissional? Desde uma perspectiva de gênero, como compreendo a participação das mulheres nas comissões legislativas e no âmbito parlamentar de um modo mais geral?

\section{PERSPECTIVA DE GÊNERO E GARANTIA DOS DIREITOS DAS MULHERES}

Fazendo uma breve incursão cronológica, além da Constituição de 1934, anteriormente destacada como a primeira norma constitucional a reconhecer o direito das mulheres ao sufrágio no Brasil, foi promulgado, na década de sessenta, o Estatuto da Mulher Casada (Lei 4.121/62), seguido pela Lei do Divórcio (Lei $6515 / 77$ ), em fins dos anos setenta. Tais leis foram 
muito importantes para o avanço das questões femininas, porém, conforme vimos, foi somente nos anos de 1980, mais precisamente com a Constituição Fede- ral de 1988, que diversas demandas especificamente femininas foram incorporadas ao texto constitucional brasileiro, tudo por força de uma conjuntura política

\begin{tabular}{|c|c|}
\hline Lei & Conteúdo ou matéria \\
\hline Lei 8009/1990 & $\begin{array}{l}\text { Dispõe sobre a impenhorabilidade do bem de família, salvaguardando interesses } \\
\text { familiares, especialmente das mulheres e filhos/as; }\end{array}$ \\
\hline Lei 8072/1990 & $\begin{array}{l}\text { Dispõe sobre os crimes hediondos, nos termos do art. } 5^{\circ} \text { da CF, incluindo o estu- } \\
\text { pro entre estes, assim como o atentando violento ao pudor; }\end{array}$ \\
\hline Lei 8560/1992 & Regula a investigação de paternidade dos filhos havidos fora do casamento; \\
\hline Lei 8.408/1992 & $\begin{array}{l}\text { Estabelece prazo para a separação judicial e determina que a mulher, ao separar-se, } \\
\text { volte a usar o nome de solteira, exceto se a alteração lhe acarrete sérios prejuízos; }\end{array}$ \\
\hline Lei 8978/1995 & Dispõe sobre a construção de creches e estabelecimentos de pré-escola; \\
\hline Leis 9.100/1995 e 9504/1997 & $\begin{array}{l}\text { Estabelecem normas para a realização das eleições municipais e nacionais e ins- } \\
\text { tituem cotas mínimas e máximas de candidaturas por sexo; }\end{array}$ \\
\hline Lei 9029/1995 & $\begin{array}{l}\text { Proíbe a exigência de atestado de gravidez e esterilização, e outras práticas dis- } \\
\text { criminatórias, para efeitos admissionais ou de permanência da relação jurídica } \\
\text { de trabalho, e dá outras providencias; }\end{array}$ \\
\hline Lei 10.406/2002 & $\begin{array}{l}\text { Institui o Código Civil, estabelecendo a igualdade de direitos na sociedade e na } \\
\text { família, em consonância com a Constituição Federal; }\end{array}$ \\
\hline Lei 10.683/2003 & $\begin{array}{l}\text { Dispõe sobre a organização da Presidência da República e dos ministérios, in- } \\
\text { cluindo a Secretaria Especial de Política para Mulheres e o Conselho Nacional } \\
\text { dos Direitos da Mulher; }\end{array}$ \\
\hline Lei $10714 / 2003$ & $\begin{array}{l}\text { Autoriza o Poder Executivo a disponibilizar, em nível nacional, número telefônico } \\
\text { destinado a atender denúncias de violência contra a mulher (o dique-denúncia } \\
\text { para coibir a violência de gênero); }\end{array}$ \\
\hline Lei $10836 / 2003$ & $\begin{array}{l}\text { Cria o Programa Bolsa-família destinado a distribuição de renda entre unidades fa- } \\
\text { miliares que se encontrem em situação de pobreza e/ou que tenham em sua compo- } \\
\text { sição gestantes, nutrizes, crianças, adolescentes e mulheres como chefe de família; }\end{array}$ \\
\hline Lei 11340/2006 & $\begin{array}{l}\text { Mais conhecida como Lei Maria da Penha, que cria mecanismos para coibir a } \\
\text { violência doméstica e familiar contra a mulher, nos termos do } \S 80 \text { do art. } 226 \text { da } \\
\text { Constituição Federal, da Convenção sobre a Eliminação de Todas as Formas de } \\
\text { Discriminação contra as Mulheres e da Convenção Interamericana para Prevenir, } \\
\text { Punir e Erradicar a Violência contra a Mulher; dispõe sobre a criação dos Juizados } \\
\text { de Violência Doméstica e Familiar contra a Mulher; altera o Código de Processo } \\
\text { Penal, o Código Penal e a Lei de Execução Penal; e dá outras providências. }\end{array}$ \\
\hline
\end{tabular}


democrática que possibilitou uma inédita participação social nas discussões e proposições de regras jurídica no Brasil. ${ }^{16}$

Após as conquistas acima mencionadas, fruto das pressões permanentes e dos diálogos e negociações entre o movimento social e o Estado, outras leis foram sendo elaboradas e/ou modificadas, sendo, em maior ou menor grau, inspiradas na perspectiva de gênero e nas contribuições feministas, tais como, dentre outras, as seguintes:0 catálogo de leis acima exposto, constitui importante exemplo do esforço desenvolvido pelo movimento feminista e de mulheres, assim como por mulheres e homens parlamentares, na construção de uma legislação mais democrática, mais inclusiva e, sobretudo, sensível ao gênero. Trata-se, portanto, de um trabalho que já soma duas décadas e meia de muito esforço, contabilizando conquistas e alguns obstáculos, mas que vai abrindo caminho e oportunidades, onde e quando é possível, para a temática de gênero, pois, apesar das vitórias transcritas, muito ainda está por fazer.

Neste contexto, é mais que necessário o engajamento de amplos setores da sociedade civil bem como dos poderes constituídos, sendo estratégico o envolvimento de parlamentares, assessores e técnicos, vez que estes, nesta empreitada, pela função que desempenham e pelo conhecimento que detém, jogam papel fundamental.

\section{UMA METODOLOGIA PARA INCORPORAR A PERSPECTIVA DE GÊNERO NO PARLAMENTO}

Como vimos, a perspectiva de gênero deve estar presente em todas as atividades parlamentares e matérias legislativas, não se restringido a um

16. Sobre a participação das mulheres na construção de leis que incorporam suas demandas específicas, conferir artigo de nossa autoria intitulado Constitucionalização dos direitos das mulheres no Brasil: um desafio à incorporação da perspectiva de gênero no Direito. Disponível em https://periodicos.set.edu.br/index.php/direito/ article/download/178/76i. setor ou grupo específico. Deve ter destaque nas agendas, Comissões, Projetos de Leis e Processo Legislativo como um todo, bem como na estrutura organizacional e nas relações entre parlamentares, funcionários(as), assessores(as) e servidores(as); não esquecendo que deve ser aplicada, também, na linguagem e redação dos discursos, pareceres, textos de lei, dentre outros, inclusive no Manual de Redação de leis e documentos oficiais, adotado pelas Casas Legislativas e seus regimentos.

Deste modo, visando integrar o enfoque de gênero nas leis e demais atos do Poder Legislativo, o pensamento jurídico feminista, nacional e estrangeiro, tem contribuído com orientações e recomendações, inclusive metodológicas, sobre como proceder no desenvolvimento das atividades realizadas nestas esferas, especialmente na produção de novas e democráticas leis. Para tanto, em alguns países da Europa, assim como na América Latina, alguns Parlamentos estão desenvolvendo, com o auxílio e assessoramento de pesquisadoras e militantes feministas, alguns métodos ${ }^{17}$, manuais $^{18}$ e guias ${ }^{19}$ destinados à integração do enfoque de gênero nestes espaços de poder. Tais esforços, pode-se dizer, estão em plena sintonia com o que prescrevem e orientam os principais instrumentos internacionais sobre

17. Sobre métodos, convém lembrar que, apesar da nomenclatura, não há exatamente um método, no sentido estrito da palavra, para se desenvolver a incorporação da perspectiva de gênero no campo legislativo, há na verdade, uma excelente metodologia desenvolvida e sistematizada por Alda Facio, denominada Metodología para el análisis de género del fenómeno jurídico, disponível no livro Cuando el Gênero Suena Cambios Trae, cuja síntese e adaptação para a análise de projetos legislativos está disponível em: http://www.saber.ula.ve/bitstream/123456789/22827/1/ articulo_1.pdf

18. Como exemplo de manual, a Assembleia Legislativa da República de Costa Rica elaborou uma Política e um Plano de Igualdade e Equidade de Gênero no âmbito do seu Parlamento, tendo como objetivo central incorporar a perspectiva de gênero nas diferentes fases do processo de elaboração das leis e na dinâmica interna da função legislativa. Disponível em: http://www.asamblea.go.cr/Centro_de_informacion/Unidad_Tecnica_Igualdad/Documents/Politica\%20de $\% 20$ Igualdad\%20y\%20Equidad\%20de\%20 G\%C3\%A9nero\%20de\%20la\%20Asamblea\%20Legislativa.pdf

19. Com relação aos guias, além da Costa Rica, México, Peru e Argentina vem desenvolvendo esforços no sentido de criar e/ou sistematizar ferramentas para auxiliar a análise de gênero do fenômeno legal, bem como visando orientar parlamentares e assessores na produção legislativa com "mirada de género". Neste sentido, em 2001 o Peru lançou um Manual com “Ferramentas de Inclusão da Perspectiva de Gênero na Produção Legislativa” e, em 2010, o governo mexicano publicou um “Guia para la Armonización Legislativa con Perspectiva de Género al Derecho Interno del Estado de México”. Disponível em: http:// cedoc.inmujeres.gob.mx/ftpg/EdoMex/edomexmeta9.pdf; http://www.unfpa.org.pe/ publicaciones/publicacionesperu/MANUELA-RAMOS-ProduccionLegislativa-Genero.pdf 
igualdade e equidade de gênero, alguns deles decorrentes das Conferências e Encontros internacionais ${ }^{20}$.

Todos os documentos acima referidos foram elaborados no sentido de orientar a incorporação da perspectiva de gênero em todo o ciclo de produção e desenvolvimento das leis, isto é, desde a iniciativa, passando pelo momento de elaboração e aprovação, até a implementação das mesmas, sugerindo-se, ainda, que tal enfoque perpasse todas as relações estabelecidas entre os atores políticos envolvidos nesta tarefa. Diante de tais desafios, que passa a exigir mudanças de ordem filosófica, material e procedimental (isto é, de valores, de conteúdo e de atuação) no trabalho realizado no âmbito das Casas Legislativas, funcionários e decisores deste Poder estatal deverão observar e operar com as lentes de gênero em todo o percurso de elaboração das leis, bem como no seu cotidiano pessoal e profissional.

Desse modo, e visando iluminar o desenvolvimento desta tarefa, passamos a expor, em apertada síntese, a metodologia construída pela jurista feminista Alda Facio, ${ }^{21}$ que consiste em seis etapas distintas, por ela chamada de seis passos que devem ser tomados como orientação mais geral, advertindo-se, no entanto, que "nem sempre temos que levar a cabo cada um deles, ou realizá-los obrigatoriamente na ordem proposta", quais sejam:

Passo 1: tomar consciência da subordinação do gênero feminino ao masculino na experiência pessoal; passo 2: identificar as distintas formas de ma-

20. Conferir a Convenção Sobre a Eliminação de Todas as Formas de Discriminação contra a Mulher, conhecida por sua sigla em inglês, CEDAW, a qual foi adotada pela Assembleia Geral das Nações Unidas em 18.12.1979, entrando em vigor em 03.09.1981. Esta Convenção foi assinada pelo Brasil, com reservas, em 31.03.1981 e ratificada, também com reservas, em 01.02.1984, passando a vigorar em nosso país em 02.03.1984. Dez anos depois, isto é, em 22.06.1994 foi ratificada novamente, agora sem reservas, e seu texto foi publicado no Diário do Congresso Nacional em 23.06.1994. Além da mencionada Convenção, que tem caráter mundial, foi elaborada, no âmbito da América Latina, a Convenção Interamericana para Prevenir, Punir e Erradicar a Violência contar a Mulher, adotada em Belém do Pará, Brasil, em 9 de junho de 1994.

21. Conforme já exposto neste texto, Alda Facio é consultora jurídica sobre questões de Gênero e Direito e autora de diversos artigos e livros nesta área, dentre eles, a obra Cuando el Género Suena Cambios Trae: metodologia para el análisis de género del fenômeno legal (ILANUD, 1999). nifestação do sexismo no texto legislativo, visando eliminá-las; passo 3: identificar qual é a mulher que, de forma visível o invisível, está no texto legal: se é a mulher branca, a mulher casada, a mulher pobre etc., quer dizer, qual é a mulher que se está contemplando como paradigma de ser humano e desde aí analisar qual ou quais são seus efeitos sobre as mulheres de distintos setores, classes, raças, etnias, crenças, orientações sexuais etc.; passo 4: identificar qual é a concepção ou estereótipo de mulher que serve de sustento ao texto, isto é, se é somente a mulher-mãe, a mulher-família, ou a mulher enquanto ser que pode se assemelhar ao homem etc.; passo 5: analisar o texto tomando em conta a influência os efeitos desta lei em outros componentes do fenômeno legal e passo 6: ampliar a tomada de consciência do que é o sexismo e coletivizá-la.

Com relação ao primeiro passo, convém destacar que a tomada de consciência se faz necessária para que a pessoa compreenda a generalização e a profundidade da discriminação e subordinação das mulheres, a fim de evitar que se perca tempo exigindo provas, a cada elaboração de nova lei, daquilo que já está suficientemente reconhecido e contemplado pela Convenção sobre a Eliminação de Todas as Formas de Discriminação contra a Mulher-CEDAW. Esta conscientização se alcança por meio da observação e reflexão da experiência pessoal e cotidiana das mulheres, a qual não deve ser considerada como uma situação meramente individual, mas como submissão coletiva decorrente das relações de gênero. Este processo implica perceber a situação e posição das mulheres em suas famílias, na sociedade e no próprio Parlamento, nas mais diversas funções.

No que diz respeito ao segundo passo, vale frisar que, conforme leciona a autora, o sexismo, enquanto crença na superioridade de um sexo sobre o outro, pode se manifestar de variadas formas. No que concerne à produção e interpretação das leis, segundo Alda Facio (1999), o sexismo apresenta-se de sete formas distintas, quais sejam: por meio do androcen- 
trismo, do dicotomismo sexual, da insensibilidade ao gênero, da sobregeneralização (e/ou a sobreespecificação), do duplo parâmetro, do dever ser de cada sexo e do familismo.

Sintetizando cada um deles, pode se dizer que o androcentrismo consiste numa forma de ver o mundo desde o masculino, isto é, tomando o varão como parâmetro do humano. A insensibilidade de gênero, por sua vez, se apresenta quando se ignora a variável sexo como uma variável socialmente importante ou válida. Já a sobregeneralização ocorre quando o diagnóstico da realidade que será normatizada analisa somente a conduta do sexo masculino e apresenta os resultados como válidos para ambos os sexos.

A sobreespecificação, que é a outra face da moeda da sobregeneralização, se refere a uma forma de sexismo em que se apresenta como específico de um sexo certas necessidades e interesses que, na realidade, são de ambos, como é o caso das questões relativas à criação, cuidados e educação dos filhos ou a temática da sexualidade e reprodução. Sobre o duplo parâmetro, diz-se que é muito semelhante à dupla moral que se estabelece socialmente para regular a conduta de homens e mulheres. 0 dicotomismo sexual consiste em tratar os sexos de modo diametralmente opostos e não com características semelhantes, quando o que está em foco não são as especificidades de cada um, mas os direitos humanos de uma maneira geral. E o familismo, por sua vez, é o tipo de sexismo que parte do princípio de que a mulher e a família são sinônimos e que, por isto, seus interesses e necessidades são os mesmos.

Sobre o terceiro passo, a autora adverte que este passo somente deve ser desenvolvido se o projeto de lei apresentado constitui uma proposta sobre mulheres ou se contempla um setor específico destas. Com relação ao quarto passo, a orientação da autora é que se deve buscar identificar qual é a representação de mulher que está implícita ou explicitamente subjacente ao texto, isto é, se somente se percebe a mulher como um ente destinado a procriar, ou como um membro a serviço da família, ou como um sujeito cujos direitos e obrigações serão garantidos no caso de se assemelhar ao homem em todas as atividades que realize, isto é, alguém a quem se deve estender os direitos masculinos já existentes nos textos legais.

O quinto passo, por seu turno, exige que se tenha claro que o fenômeno jurídico não se restringe ao sistema de normas, cujos destinatários sãos os membros da sociedade politicamente organizada, afinal, ele é mais do que isto: se constitui de ordenamento, instituições e valores, os quais correspondem aos componentes formal-normativo, estrutural e político-cultural. Todos estes componentes se interdependem e se retroalimentam, o que significa dizer que ao analisar o conteúdo de um projeto ou mesmo de uma lei, deve-se tomar em conta os efeitos que esta poderá causar não apenas no ordenamento, mas nas instituições e nos valores em voga em cada sociedade, em dado momento histórico.

Por fim, o sexto passo sugere a mais ampla democratização do processo de feitura da lei. Propõe que a mesma seja amplamente discutida pelos diversos atores sociais, notadamente os destinatários e/ou beneficiários da norma, a fim de que, em todas as fases, sejam expostas as questões e problemas sobre os quais a lei incidirá, o que leva a uma permanente tomada de consciência por parte dos legiladores, dos decidores e dos elaboradores da lei.

\section{UMA METODOLOGIA PARA INCORPORAR A PERSPECTIVA DE GÊNERO NO PROCESSO LEGISLATIVO}

No mesmo sentido do que foi discutido anteriormente, porém numa perspectiva ainda mais específica, isto é, no tocante ao processo de iniciativa da lei propriamente dito, a Organização das Nações Unidas, mais particularmente o setor dedicado às Políticas de 
Agricultura e Alimentação-FAO ${ }^{22}$, orienta que, inicialmente, deve ser feito um diagnóstico ${ }^{23}$ sobre o estado e/ou condição da matéria a ser legislada, o qual deve incidir sobre alguns aspectos específicos. 0 primeiro deles sugere observar se a iniciativa de lei visa modificar ou revisar uma norma já existente, pois é importante verificar se tal iniciativa implicará em revogação total ou parcial da norma e, em caso afirmativo, analisar os vários aspectos da lei que se encontra em processo de revogação; avaliar a atualidade e pertinência da lei face às exigências sociais, conhecendo, pormenorizadamente, os indicadores de gênero na sociedade em questão; avaliar o propósito e o alcance da legislação com relação às outras leis existentes e sua integração no regime jurídico no qual se insere; analisar a aplicabilidade da mesma nos últimos anos (consoante uma visão de gênero); identificar conflitos gerados pela lei, formas e mecanismos de solução dos mesmos; identificar lacunas e/ ou omissões legislativas; conhecer as razões reais da alteração e da revisão legislativa.

Já o segundo aspecto se refere à iniciativa de lei sobre matéria ainda não legislada. Neste caso, orienta-se que seja analisado o contexto socioeconômico e cultural no qual a lei será inserida, especialmente as relações e papéis de gênero vigentes, observando-se, em particular o seguinte: as possíveis situações de discriminação e conflitos decorrentes da omissão legislativa; os beneficiários e os atores direta e indiretamente envolvidos na iniciativa, assim como as relações de gênero que a lei poderá influenciar na sociedade como um todo; a pertinência da lei para os seus principais destinatários, verificável mediante diálogos abertos com os atores envolvidos que poderão compor grupos de trabalho constituídos por representantes da sociedade civil e dos setores público e privado.

22. Tais orientações estão contidas num guia elaborado especificamente para orientar a integração da perspectiva de género na legislação relativa à terra e águas especialmente em países lusófonos do continente africano. Este documento encontra-se disponível no seguinte endereço eletrônico: http://www.fao.org/fileadmin user_upload/legal/docs/1_lpo88-p.pdf

23. Esta análise, conforme o órgão referido, permite elaborar e compreender melhor a iniciativa legislativa, possibilitando uma revisão mais próxima às exigências sociais e uma melhor integração da perspectiva de gênero.
No que diz respeito ao processo de elaboração da lei, que constitui a segunda etapa do ciclo de vida da mesma, as orientações indicam o seguinte: analisar as recomendações constantes das conclusões do diagnóstico, realizadas na fase da iniciativa legislativa, que devem ter sido discutidas e socializadas com os(as) beneficiários(as) da lei e/ou seus representantes; procurar realizar os direitos reconhecidos na Constituição Federal e nos instrumentos jurídicos internacionais ratificados ${ }^{24}$; integrar as normas positivas $^{25}$ nas situações onde persiste a desigualdade e iniquidade de género; garantir a participação de todos os atores envolvidos, dialogando e negociando o texto final da lei.

Quanto à aprovação, deve ser validada publicamente, pelos vários atores, especialmente por meio de amplos debates, campanhas e ações educativas 26 . Já no que diz respeito à aplicação e implementação legal, faz-se necessária a readequação institucional ${ }^{27}$, assim como a capacitação dos responsáveis por esta atividade, em matérias relativas à temática e, sendo possível, a criação de comissão de acompanhamento e monitoramento da implementação da lei.

Alguns manuais, em especial o guia da Food and Agriculture Organization ${ }^{28}$ (FAO) sobre a incorporação da perspectiva de gênero no âmbito legislativo, tomado neste texto como base para a presente reflexão, trazem ainda o quesito avaliação no ciclo da produção legislativa, advertindo, no entanto, para o fato de que inexistem nos ordenamentos jurídicos dos diversos países previsões para a realização desta atividade. A

24. Tais como Tratados e Convenções internacionais dos quais o país seja signatário 25. Normas jurídicas já existentes relativas a temática, tais como Constituição Federal e outras normas complementares ou ordinárias, mas que tratem do mesmo assunto, tal como leis federais e estaduais, caso se trate de um projeto de Lei Municipal.

26. Esta orientação visa demonstrar o caráter democrático da produção legislativa, através do qual, presume-se que houve amplo diálogo entre o poder legislativo e os atores sociais envolvidos na elaboração da mesma, o que possibilita um maior conhecimento e aceitação das regras.

27. Neste caso, trata-se da criação e órgãos e equipamentos destinados a garantir a implementação da lei, bem como a capacitação dos profissionais que operarão na interpretação e aplicação da norma, tal como aconteceu com as Leis Maria da Penha, onde foi necessário a criação dos Juizados e Varas especializadas, e o Estatuto da Criança e do Adolescente, por exemplo.

28. Organização das Nações Unidas para a Alimentação e a Agricultura. 
constatação desta ausência deve servir de estímulo para que as Casas Legislativas venham um dia a incluir na sua agenda a temática da avaliação periódica dos textos legais, bem como a criação de mecanismos que possibilitem tal objetivo.

Além disso, esses manuais orientam no sentido da criação de um conjunto de indicadores que possam ser negociados e convencionados no processo de elaboração da lei, onde se pode definir previamente as responsabilidades do Governo e dos demais atores implicados nesta tarefa. Tal mecanismo, apesar de não haver exemplos claros nos manuais, poderia ser um fórum, uma recurso, uma audiência pública, ou outro mecanismo legal que se constituiria num espaço privilegiado para integração da perspectiva de gênero na própria implementação e avaliação da lei, já que esta experiência, guardada as devidas proporções, já vem sendo vivenciada no âmbito da Justiça, notadamente por meio da figura do amicus curiae $^{29}$ que tem possibilitado um diálogo democrático, aberto e plural entre grupos sociais, coletivos específicos e a alta cúpula do Poder Judiciário brasileiro, especialmente em matérias polêmicas como cotas para afrodescendentes, aborto de anencéfalos, união entre pares do mesmo sexo, dentro outras.

\section{CONCLUSÃO}

Conforme o exposto percebe-se que o movimento/pensamento feminista, tanto no Brasil como alhures, seja por meio de sua ação política e/ou das múltiplas reflexões acadêmicas, materializadas nas teorias e metodologias específicas, tem muito a contribuir para a democratização e o aprimoramento dos espaços decisórios.

No que tange ao Parlamento especificamente, o movimento/pensamento feminista não somente

29. Esta expressão, que costuma ser traduzida como Amigos da Corte, foi inspirada nas contribuições teóricas do jurista alemão Peter Haberle, autor da obra Hermenêutica Constitucional: A Sociedade Abertas dos Intérpretes da Constituição, a qual influenciou na construção da figura processual no texto referida, bastante acionada no Brasil pelos movimentos sociais e grupos específicos, especialmente nos processo cuja matéria envolve a solução de casos difíceis (hard cases) em trâmite no Supremo Tribunal Federal. tem identificado e denunciado a sub-representação das mulheres na política, como tem pugnado por uma maior participação destas nas instâncias de poder e proposto a incorporação da perspectiva de gênero na atuação e na produção legislativa de um modo geral, vez que já foi abundantemente demonstrado que as leis e os demais atos normativos impactam de maneira diferenciada sobre a vida de homens e mulheres.

Visando contribuir para a incorporação da chamada perspectiva de gênero no Parlamento, o presente texto trouxe algumas reflexões sobre a temática, apresentando, de maneira simples e didática, a relevância desta perspectiva, destacando alguns exemplos de Parlamentos e de leis (in)sensíveis ou cegas ao gênero, assim como uma pequena amostra de metodologias destinadas à realização deste desiderato, ou seja, à implementação desta visão no processo de feitura das normas.

Assim sendo, espera-se que esta discussão, que ainda é incipiente no Brasil, possa não somente ser aprofundada mas, sobretudo incorporada ao cotidiano democrático nacional e às suas distintas esferas de produção legislativa.

\section{REFERÊNCIAS}

BALAGUER, María Luisa. Mujer y Constitución. La construcción jurídica del género. Madrid: Ediciones Cátedra, 2005.

BIRGIN, Haydée. Identidad, diferencia y discurso feminista. Universalismo frente a particularismo. In: BIRGIN, Haydée (org.). El derecho en el género y el género en el derecho. Buenos Aires: Biblos, 2000.

BONAVIDES, Paulo e ANDRADE, Paes. História Constitucional do Brasil. Brasília, DF: Senado Federal/ Paz e Terra Política, 1988. 
COSTA, Ana Alice Alcântara Costa. 0 movimento feminista no Brasil: dinâmicas de uma intervenção política. Disponível em: <http://www.unb.br/ih/his/ gefem/labrys7/liberdade/anaalice.htm 2005>. Acesso em: 19 dez. 2014.

DAHL, Tove Stang. O Direito das Mulheres: uma introdução à teoria do direito feminista. Trad. Teresa Beleza et al. Fundação Calouste Gulbenkian. Lisboa, 1993.

FACIO MONTEJO, Alda. Cuando el género suena cambios trae. Metodologia para el análisis de género del fenómeno legal. San José, C.R: ILANUD, 1999.

FRIES, Lorena; FACIO, Alda et al. (Orgs.). Género y Derecho. Santiago: LOM Ediciones/La Morada, 1999.

GAMBA, Susana B (Org.). Dicionário de Estúdios de Género y Feminismo. Buenos Aires: Biblios, 2007.

GUIA para La Armonización Legislativa con Perspectiva de Género al Derecho Interno del Estado de México. 2010. Disponível em: <http://cedoc.inmujeres. gob.mx/ftpg/EdoMex/edomexmeta9.pdf>. Acesso em: 17 dez. de 2014.

GUIÃO para a Integração da Perspectiva de Gênero na Legislação Relativa a Terra e Águas em Angola, Cabo Verde e Moçambique. Food Agriculture Organization of the United Nations. BORGES, Luísa et al (orgs). FAO LEGAL PAPERS ONLINE, N.88, 2011. Disponível em: <http://www.fao.org/fileadmin/ user_upload/legal/docs/1_lpo88-p.pdf>. Acesso em: 15 dez. 2014.

HABERLE, Peter. Hermenêutica Constitucional: A Sociedade Abertas dos Intérpretes da Constituição. Trad. Gilmar F. Mendes. Porto Alegre: Sérgio Fabris, 1997.

HARDING, Sandra. Ciencia y feminismo. Madrid: Morada, 1996.
HARDING, Sandra. Existe um método feminista? In: BARTRA, Eli. (Org.). Debates em torno a uma metodologia feminista. México. DF: UNAM, 1988, p.9-34.

KOHEN, Beatriz. El feminismo jurídico en los países anglosajones: el debate actual. In: BIRGIN, Haydée (org.). El derecho en el género y el género en el derecho. Buenos Aires: Biblos, 2000.

MENACHE, Daniel Cazés. La perspectiva de género. Guía para diseñar, poner em marcha, dar seguimento y avaluar proyetos de investigación y acciones públicas y civiles. Ciudad de México: CONAPO; Instituto Nacional de la Mujer, 2005.

MORENO, Amparo. El arquétipo viril protragonista de la história. Ejercicios de lectura no androcentrica. Cuadernos Inacabados. Barcelona: La Sal, 1987, p.17- 52.

PIEGAL. Política de Igualdad y Equidad ee Género. Asamblea Legislativa de Costa Rica, 2013. Disponível em: <http://www.asamblea.go.cr/Centro_de_informacion/Unidad_Tecnica_Igualdad/Documents/ Politica\%20de\%20Igualdad\%20y\%20Equidad\%20 de $\% 20$ G\%C3\%A9nero\%20de\%20la\%20Asamblea\%20Legislativa.pdf>. Acesso em: 12 dez. 2014.

PHILIPIS, Anne. Género y Teoría Democrática. México: PUEG/UNAM, 1996.

PIOVESAN, Flávia. Temas de direitos humanos. São Paulo: Saraiva, 2009.

SARDENBERG, Cecília. Da crítica feminista à ciência a uma ciência feminista? In: COSTA, Ana Alice Alcântara; SARDENBERG, Cecília Maria Bacelar. (Orgs.) Feminismo, ciência e tecnologia. Salvador: REDOR/ NEIM-FFCH/UFBA, 2002, p.89-120.

SILVA, Salete Maria da. Constitucionalização dos direitos das mulheres no Brasil: um desafio à incorporação da perspectiva de gênero no Direito. Interfaces Científicas - Direito. Aracaju, v.1., n.1, 
out. 2012, p. 59-69. Disponível em:

$<$ https://periodicos.set.edu.br/index.php/direito/article/download/178/76i>. Acesso em: 11 dez. 2014

SMART, Carol. La teoria feminista y el discurso jurídico. In: BIRGIN, Haydée (org.). El derecho en el género y el género en el derecho. Buenos Aires: Biblos, 2000.

TELES, Maria Amélia de Almeida. Breve história do feminismo no Brasil. São Paulo: Braziliense, 1999.
ULLOA CUÉLLAR, Ana Lília. Género, Derecho y Democracia. Veracruz, México: Gobierno del Estado, 2007.

WEST, Robin. Género y teoria del Derecho. Traductor Pedro Lama. Bogotá: Siglo del Hombre/Instituto Pensar, 2000. 